Asian J. Med. Biol. Res. 2016, 2 (4), 689-695; doi: 10.3329/ajmbr.v2i4.31016

\author{
Asian Journal of \\ Medical and Biological Research \\ ISSN 2411-4472 (Print) 2412-5571 (Online) \\ www.ebupress.com/journal/ajmbr
}

\title{
Article \\ Species identification and the biological properties of several Japanese starfish
}

Farhana Sharmin*, Shoichiro Ishizaki and Yuji Nagashima

Graduate School of Marine Science and Technology, Tokyo University of Marine Science and Technology, Konan 4-5-7, Minato, Tokyo108-8477, Japan

*Corresponding author: Farhana Sharmin, Graduate School of Marine Science and Technology, Tokyo University of Marine Science and Technology, Konan 4-5-7, Minato, Tokyo 108-8477, Japan. E-mail: ginisaz05@yahoo.co.in

Received: 07 December 2016/Accepted: 20 December 2016/ Published: 29 December 2016

\begin{abstract}
Marine organisms are a rich source of natural products with potential secondary metabolites that have great pharmacological activity. Starfish are known as by-catch products in the worldwide fishing industry and most of starfish have been got rid of by fire destruction without any utilization. On the other hand, starfish are considered as extremely rich sources of biological active compounds in terms of having pharmacological activity. In the present study, molecular identification of starfish species, micronutrient content and hemolytic activity from Luidia quinaria, Astropecten scoparius, and Patiria pectinifera were examined. Nucleotide sequence analysis of the 16S rRNA gene fragment of mitochondrial DNA indicated that partial sequences of PCR products of the species was identical with that of L. quinaria, A. scoparius, and P. pectinifera. From the results of micronutrient contents, there were no great differences on the micronutrient among species. However, $\mathrm{Cd}, \mathrm{Cu}$, and as contents had species-specificity. The crude extract of three starfish showed hemolytic activity against $2 \%$ rabbit erythrocytes with $50 \%$ hemolytic concentration of $10-1000 \mu \mathrm{g} / \mathrm{mL}$. The findings of the present study provided some basic information about identification of starfish species, potentialities of starfish which could be utilized in food and pharmaceutical industry.
\end{abstract}

Keywords: starfish; identification; micronutrient content; hemolytic activity

\section{Introduction}

Starfish are star-shaped echinodermata, belonging to the class Asteroidea. The large outbreak of starfish has been observed in worldwide ocean. Starfish have the ability to consume a wide range of food source including mussels, scallops, clams, and some seabed fish, which causes considerable decline in the number of commercial shellfish (Global Invasive Species Database, 2016). Starfish are considered as an extremely rich source of biologically active components, such as glycosylceramide, steroidal glycosides, ceramide, and cerebrosides (Inagaki et al., 2006; Ishii et al., 2006; Suh et al., 2011). Steroidal glycosides are the main metabolites of starfish and possess most toxicity (D'Auria et al., 1993). In particular, steroidal glycosides and related compounds are predominant metabolites in starfish and have a broad variety of biological activities such as cytotoxic, hemolytic, ichthyotoxic, repellent, antineoplastic, antimicrobial, antifungal, antiviral and antiinflammatory (Lee et al., 2014; Thao et al., 2014; Nina et al., 2003).

Starfish has identified as a serious pest species because of its ability to consume a wide range of food sources including mussels, scallops, and clams (Global invasive species database, 2016). The wastes of them results in serious environmental pollution. Furthermore the large outbreak of starfish causes significant loss of the marine ecosystem and fishing gears (Kim, 1969). There is no effective method to control these large outbreaks of starfish. Extensive investigations of starfish, chemically and pharmacologically analysis in now demanded for utilization of starfish resources. 
Therefore, it is necessary to identify the starfish species and to know their biological properties for advanced utilization. Firstly starfish species identification was done by PCR amplification method and then micronutrient content of starfish was evaluated. In addition, hemolytic activity was determined and the activity was compared with two other plant saponins, quillaja bark and ted seed.

\section{Materials and Methods}

\subsection{Sample collection}

Luidia quinaria, Astropecten scoparius, and Patiria pectinifera was collected from the coast of Kobe, Hyogo prefecture, Japan in February 2014 and immediately brought to the laboratory in fresh conditions in ice. Freshly collected samples were immediately washed to remove mud and other particles and subsequently stored at $60^{\circ} \mathrm{C}$ until use.

\subsection{Species identification based on DNA analysis}

Genomic DNA was extracted from tube feet of starfish sample by using Quick gene-810 (Kurabo, Tokyo, Japan) as recommended by the manufacturer. The DNA concentration $(\mathrm{ng} / \mu \mathrm{L})$ was measured by a Biospec Nano (Shimadzu Corporation, Tokyo, Japan). A partial region of the mitochondrial 16S rRNA gene was amplified by the conventional polymerase chain reaction (PCR) using universal primers (16SarL, 5'CGCCTGTTTATCAAAAACAT-3' and 16SbrH, 5'-CCGGTCGAAACTCAGATCACGT-3'). Briefly, the reaction mixture for PCR was carried out in the $50 \mu \mathrm{L}$ volume containing $5 \mu \mathrm{L}(50 \mathrm{ng})$ of genomic DNA, $4 \mu \mathrm{L}$ of dNTP $(2.5 \mathrm{mM}$ each), $5 \mu \mathrm{L}$ of $10 \times$ Ex Taq buffer, $0.4 \mu \mathrm{L}$ of Ex Taq DNA polymerase (Takara Shuzo, Japan) $(5 \mathrm{U} / \mu \mathrm{L})$, and $1.5 \mu \mathrm{L}$ of $20 \mu \mathrm{M}$ of each primer,16SarL and 16SbrH. PCR amplification was performed with Veriti thermal cycler (Applied Biosystems, Foster City, CA, USA) under the following conditions: 30 cycles consisting of denaturation at $98^{\circ} \mathrm{C}$ for $10 \mathrm{~s}$, annealing at $53^{\circ} \mathrm{C}$ for $30 \mathrm{~s}$ and extension at $72^{\circ} \mathrm{C}$ for $60 \mathrm{~s}$. The amplified PCR products were run in $1.2 \%$ agarose gel containing SYBR Safe DNA Gel Stain (Invitrogen, Carlsbad, CA, USA). The gel was run at $100 \mathrm{~V}$ for $30 \mathrm{~min}$ and visualized using LAS-4000 mini documentation system (Fujifilm Cooperation, Tokyo, Japan). The PCR samples were sequenced with BigDye ${ }^{\circledR}$ terminator V3.1 Cycle Sequencing Kit and ABI 3130 Genetic Analyzer (Applied Biosystems, Foster City, CA, USA) and the obtained sequence data were analyzed by SeqEd Version 1.0.3 (Perkin Elmer, Foster City, CA, USA) software. The sequences were subjected to blast search with national center for biotechnology information (NCBI) data base. These sequences were then aligned using the default settings in ClustalW package in the MEGA 6 software (Tamura et al., 2013).

\subsection{Analysis of inorganic components}

The micronutrient content of starfish was determined. Briefly, $1 \mathrm{~g}$ of sample was dissolved in a furnace and diluted to $200 \mathrm{~mL}$ with $1 \mathrm{~N} \mathrm{HCl}$, and the diluted solution was analyzed using combustion thermal conductivity (CTC) and inductively coupled plasma spectrophotometer (ICP) method. Moisture content was determined with minced starfish sample by drying in an oven at a temperature of $105^{\circ} \mathrm{C}$ for $5 \mathrm{~h}$.

\subsection{Preparation of crude extracts}

The extraction procedure was followed according to the method described by Yasumoto et al. (1966). The sample preparation method with various solvents is shown in Figure 3. Briefly, one kilogram of starfish was cut into small pieces and then minced using a food grinder (Kitchen Aid, St. Joseph, Michigan, USA). The extraction was carried out with $3 \mathrm{~L}$ of methanol and repeated twice with $2 \mathrm{~L}$ of methanol. The extract was filtered through Whatman filter paper No. 2. The filtrate was concentrated up to $250 \mathrm{~mL}$ with a rotary evaporator (EYELA, Tokyo, Japan) under reduced pressure at $45^{\circ} \mathrm{C}$. The concentrate was stirred with an equal volume of water $(250 \mathrm{~mL})$ and defatted with $250 \mathrm{~mL}$ benzene. After being freed from benzene, $\mathrm{pH}$ of the extract was adjusted to 3 with $1 \mathrm{~N}$ hydrochloric acid and then neutralized using $1 \mathrm{~N}$ sodium hydroxide. The extract was dialyzed through an ultra-filtration membrane (MWCO: 1000, Millipore-amicon, Billerica, MA, USA) and then partitioned with $n$-butanol three times. After the $n$-butanol extract was concentrated up to $150 \mathrm{~mL}$, three volume of diethyl ether and a half volume of water were added. Finally, the aqueous layer was freeze-dried.

\subsection{Hemolytic activity}

Rabbit blood was obtained from the Japanese Biological Center (Tokyo, Japan). Hemolytic activity was determined according to the method described by Charles et al. (2009) with slight modifications. Briefly, $2 \mathrm{~mL}$ of aliquot of blood were washed three times with phosphate buffer saline (PBS) solution $(0.15 \mathrm{M} \mathrm{NaCl}-0.01 \mathrm{M}$ Tris- $\mathrm{HCl}, \mathrm{pH} 7.0$ ) by centrifugation at $1,090 \times g$ for $5 \mathrm{~min}$ at $4{ }^{\circ} \mathrm{C}$. Washed erythrocytes were suspended in the 
PBS solution to obtain a concentration of $2 \%$. Then, $0.5 \mathrm{~mL}$ of erythrocytes and $1 \mathrm{~mL}$ of PBS solution were mixed with $0.5 \mathrm{~mL}$ diluents containing $1,5,10,50,100,500$, and $1,000 \mu \mathrm{g} / \mathrm{mL}$ of individual crude starfish saponin in PBS solution. The mixtures were incubated for $30 \mathrm{~min}$ at $37^{\circ} \mathrm{C}$ and centrifuged at $270 \times g$ for $5 \mathrm{~min}$. A volume of $1.5 \mathrm{~mL}$ PBS and distilled water were used as minimal and maximal hemolytic controls, respectively. After centrifugation, the presence of a suspension of a uniform red color was considered to indicate hemolysis, and a button formation in the bottom of the wells constituted a lack of hemolysis. A volume of 250 $\mu \mathrm{L}$ of each supernatant was transferred to a 96-well flat bottom micro plate, and the absorbance at $540 \mathrm{~nm}$ was measured with a micro plate reader (680 Microplate readers, BIO-RAD, Tokyo, Japan). The experiment was done in triplicate, and each sample was transferred three times into a 96-well micro plate. The concentrations that induced hemolysis of $50 \%$ of erythrocytes hemolysis $\left(\mathrm{HC}_{50}\right)$ in the different crude extract were calculated. Quillaja bark and Tea seed saponins were obtained from Wako Pure Chemical industry (Osaka, Japan) and Sigma Aldrich (St. Louis, MO, USA), respectively, and were used for comparison with starfish extract. All experiments were done in triplicate for the analysis of each $\mathrm{HC}_{50}$ and expressed as mean \pm standard deviation (SD).

\section{Results and Discussion}

\subsection{Identification of starfish species}

Molecular identification of starfish by DNA-based method was carried out by a direct DNA sequencing analysis. Partial nucleotide sequence data of 16S rRNA gene was compared with NCBI gene data base. Figure 1 shows agarose gel electrophoresis results and Figure 2 shows aligned DNA sequences of the amplified partial 16S rRNA region from L. quinaria, A. scoparius, and P. pectinifera. Sequencing analysis confirmed that the PCR products of three species of starfish had $99 \%$ identity with the partial regions. Molecular identification of starfish is enabled by using the nucleotide sequence encoding $16 \mathrm{~S}$ rRNA gene of mtDNA. From the results of the alignment with the estimated species, it was found that the partial sequences of the PCR products from four samples were almost identical with those of $L$. quinaria (99.20\%), A. scoparius (99.17\%), and P. pectinifera (99.06\%) (Table 1).Thus, it was confirmed that identification of starfish is enabled by using the nucleotide sequence encoding 16S rRNA gene of mtDNA. Based on mitochondrial 16S rDNA sequences, Wada et al. (1996) suggested that the Luidiidae (L. quinaria) is a sister group of the rest of asteroids, including the Astropectinidae. It was hypothesized that the universal primer (16SarL and 16SbrH) could be amplified the partial region of $L$. quinaria, A. scoparius, and P. pectinifera. As a result, partial $16 \mathrm{~S}$ rRNA region of all the starfish used in this study could be amplified by using the universal primers (Figure 1). PCR products of $L$. quinaria, A. scoparius, and $P$. pectinifera had a length of approximately $500 \mathrm{bp}$ (Figure 2).

\subsection{Analysis of inorganic components}

The result of moisture and micronutrient content of three starfish L. quinaria, A. scoparius, and P. pectinfera are shown in Table 2. The $\mathrm{Cu}$ content was found in P. pectinfera with the value of $10.0 \mu \mathrm{g} / \mathrm{g}$ and followed by $A$. scoparius. The As and Cd content were found higher in P. pectinfera with the value of $2.10 \mu \mathrm{g} / \mathrm{g}$. Likewise, high level of $\mathrm{Ca}$ content was observed in A. scoparius with $16.30 \%$ of dry weight in the inorganic analysis coupled and relative high level of $\mathrm{C}$ content was found in P. pectinfera with $9.00 \%$ dry weight. Furthermore, the water content was observed higher in L. quinaria with $64.20 \%$ followed by P. pectinfera. The results of Table 2 showed that there are no great differences on the micronutrient content among starfish species. However, Cd, $\mathrm{Cu}$, and As contents had species-specificity. $\mathrm{Ca}$ and $\mathrm{P}$ are minerals that have an important role to the development and maintenance of the skeleton, together with many other physiologic functions in the body. Ca content was found to be higher in A. scoparius with $16.30 \%$ followed by L. quinaria with $10.60 \%$. On the other hand, moisture content of the starfish $L$. quinaria was detected as $64.2 \%$, which was higher to the starfish of $A$. planci with the value of 67.7 to $69.1 \%$ by weight (Luo et al., 2011). When formulating diets for animals (pigs, chicken, and fish) or fertilizer for agriculture sector, it is necessary to consider an appropriate amount of micronutrient content since excess or deficiency in one of the minerals will cause impaired utilization of the other (Gonzalez-Vega et al., 2013). Living starfish contain on average $1.65 \% \mathrm{~N}$ and $0.15 \% \mathrm{P}$ of wet weight. Therefore, the removal of 10,000 $\mathrm{t}$ of starfish, would directly remove approximately $165 \mathrm{t} \mathrm{N}$ and $15 \mathrm{tP}$ from the coastal area (Petersen et al., 2014). Nitrogen is considered to be the most important nutrient, and plants absorb more than any other elements. Thus, starfish has a great possibility to use as plant growth enhancer.

\subsection{Hemolytic activity}

Hemolytic activity of starfish saponin was evaluated using rabbit erythrocytes. Positive control (100\% hemolysis) by distilled water and negative control ( $0 \%$ hemolysis) by PBS were used as standard references. 
The activity was expressed as the concentrations inducing $50 \%$ of erythrocytes hemolysis $\left(\mathrm{HC}_{50}\right)$ and $\mathrm{HC}_{50}$ was determined at the concentrations of $10-100 \mu \mathrm{g} / \mathrm{mL}$. The $\mathrm{HC}_{50}$ values indicate that starfish crude extract $L$. quinaria, A. scoparius, and $P$. pectinifera, induced hemolysis against rabbit erythrocyte with $\mathrm{HC}_{50}$ values of $34.1 \pm 4.00,37.8 \pm 2.16$, and $31.1 \pm 6.52 \mu \mathrm{g} / \mathrm{mL}$, respectively (Figure 4). Furthermore, the $\mathrm{HC}_{50}$ values of plant saponins $(18.6 \pm 2.51 \mu \mathrm{g} / \mathrm{mL}$ for quillaja bark and $27.0 \pm 5.94 \mu \mathrm{g} / \mathrm{mL}$ for tea seed) were significantly different from those of starfish crude extract such as L. quinaria, A. scoparius, and P. pectinifera. The present results support the findings that Imamichi and Yokoyama (2013) reported that crude extract from pyloric caeca of Asterias amurensis showed high hemolytic activity in rabbit erythrocytes. The crude extract of Ophiocoma erinaceus showed hemolytic activity at $80 \%$ ethanol fraction against rat erythrocytes (Amini et al., 2014). Pant saponin and starfish extract showed different hemolytic activity. Choi et al. (2001) reported that all saponins not have hemolytic activity.

Table 1. Homology analysis results of sequence.

\begin{tabular}{llll}
\hline Sample no & Species name & Identities & Max identity \\
\hline A & Luidia quinaria & $498 / 502$ & $99.20 \%$ \\
B & Astropecten scoparius & $453 / 457$ & $99.17 \%$ \\
C & Patiria pectinifera & $525 / 530$ & $99.06 \%$ \\
\hline
\end{tabular}

Table 2. Micronutrient contents of three starfish collected from Japan.

\begin{tabular}{llcccl}
\hline Content & Unit & L. quinaria & A. scoparius & P. pectinfera & Method \\
\hline Water & $\%$ & 64.20 & 50.00 & 58.90 & $105^{\circ} \mathrm{C}$ \\
$\mathrm{C}$ & $\%$ & 6.50 & 7.70 & 9.00 & $\mathrm{CTC}$ \\
$\mathrm{N}$ & $\%$ & 0.87 & 0.67 & 1.60 & $\mathrm{CTC}$ \\
$\mathrm{P}$ & $\%$ & 0.05 & 0.04 & 0.06 & $\mathrm{ICP}$ \\
$\mathrm{K}$ & $\%$ & 0.49 & 0.48 & 0.93 & $\mathrm{ICP}$ \\
$\mathrm{Na}$ & $\%$ & 0.25 & 0.28 & 0.34 & $\mathrm{ICP}$ \\
$\mathrm{Ca}$ & $\%$ & 10.60 & 16.30 & 10.40 & ICP \\
$\mathrm{Mg}$ & $\%$ & 0.78 & 1.50 & 1.00 & $\mathrm{ICP}$ \\
$\mathrm{Cd}$ & $\mu \mathrm{g} / \mathrm{g}$ & 0.03 & 0.05 & 1.70 & $\mathrm{ICP}$ \\
$\mathrm{Cu}$ & $\mu \mathrm{g} / \mathrm{g}$ & 2.50 & 4.90 & 10.00 & ICP \\
$\mathrm{Pb}$ & $\mu \mathrm{g} / \mathrm{g}$ & 0.64 & 0.58 & 0.43 & ICP \\
$\mathrm{Hg}$ & $\mu \mathrm{g} / \mathrm{g}$ & 0.02 & 0.01 & 0.06 & $\mathrm{AAS}$ \\
$\mathrm{As}$ & $\mu \mathrm{g} / \mathrm{g}$ & 0.77 & 0.92 & 2.10 & ICP \\
\hline
\end{tabular}

CTC, comblustion thermal conductivity method; ICP, inductively coupled plasma spectrophotometer method; AAS, atomic absorbtion spectrometer method.

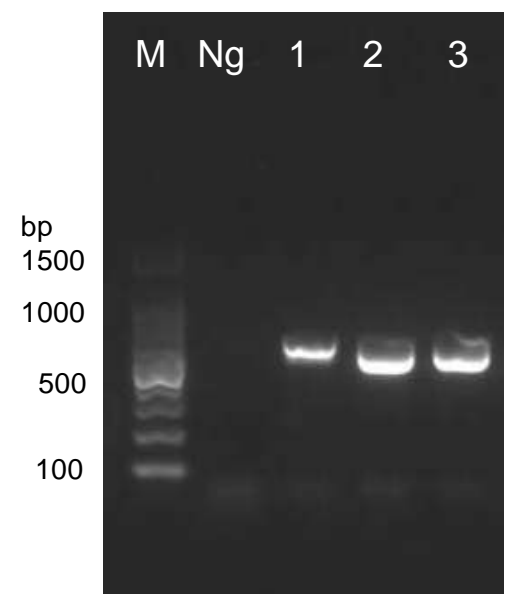

Figure 1. 1.2\% agrose gel electrophoresis of PCR amplified product. M, 1500 bp DNA ladder. A, B, and C were samples $L$. quinaria, A. scoparius and P. pectinifera, respectively. Universal primers 16SAR-L, 5'CGCCTGTTTATCAAAAACAT- 3' and 16SBR-H, 5'- CCGGTCTGAACTCAGA TCACGT- 3' for partial 16S rRNA gene were used. 
(A)

Sample A

Luidia quinaria

Sample A

Luidia quinaria

Sample A

Luidia quinaria

Sample B

Luidia quinaria

Sample A

Luidia quinaria

Sample A

Luidia quinaria

Sample B

Luidia quinaria

Sample A

Luidia quinaria

Sample A

Luidia quinaria
- CTGCCCAGTGACT TAGT T AAACGGCCGCGGTATCT TGACCGTGCAAAGgTAGCATAA 57 TGCCTGCCCAGTGACTTAGTTAAACGGCCGCGGTATCTTGACCGTGCAAAGGTAGCATAA 60 $* * * * * * * * * * * * * * * * * * * * * * * * * * * * * * * * * * * * * * * * * * * * * * * * * * * * * * * * *$

TCATTTGCCTCTTAAATAGAGGCTGGTATGAATGGCAAGACTGGGGTTAAGCTGTCTCTT 117 T CATTTGCCTCTTAAATAGAGGCTGGTATGAATGGCAAGACTGGGGTTAAGCTGTCTCTT 120

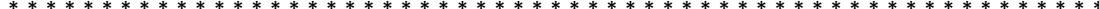

TCTTATAACT TGAATTT TATATTTTCGTGAAGAAGCGGAAATAAACT C GTAGGACGAGAA 177 TCT TATAACT TGAAT T T TATATT T T CGTGAAGAAGCGGAAATAAACT CGTAGGACGAGAA 180 $* * * * * * * * * * * * * * * * * * * * * * * * * * * * * * * * * * * * * * * * * * * * * * * * * * * * * * * * * * * *$

GACCCTGTCGAGCTTTAGTAAAAATATTAGTGGTAATAAAGAATAATAAATCTAATGTTA 237 GACCCTGTCGAGCTTTAGTAAAAATATTAGTGGTAATAAAGAATAATAAATCTAATGTTA 240 $* * * * * * * * * * * * * * * * * * * * * * * * * * * * * * * * * * * * * * * * * * * * * * * * * * * * * * * * * * * *$

\section{AACTTATAAAAATTTATAAAATCTAATTTTTTATTCTTAGCCTTTTAATATACTAACTT 297} AACT TATAAAAATT T TATAAAAT CTAATT T T TATTCTTAGCCCTT TAATATACTAACT T 300

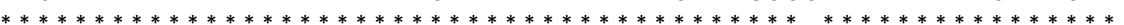

TGATTGGgGCAATCGCGGAGTATAAAAATCCTCCGCTAAAAACATAAAAAA- TAACCATT 356 TGATTGGgGCAAT CGCGGAGTATAAAAAGCCTCCGCTAAAAACATAAAAAAATAACCATT 360 $* * * * * * * * * * * * * * * * * * * * * * * * * * * * \quad * * * * * * * * * * * * * * * * * * * * * * \quad * * * * * * * *$

TTAAAATAAAGTGATCCGCTACATAGCGAGCAAAgGA ATAGTTACCGCAGgGATAACAg 416 T AAAATAAAGTGATCCGCTAGATAGCGAGCAAAGGAAT AAGT TACCGCAGGGATAACAG 420

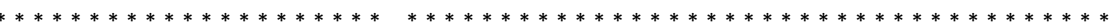

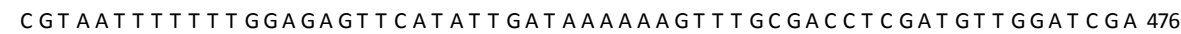
CGTAATTTTTTGGAGAGT T CATATTGATAAAAAATT TGCGACCTCGATGTTGGATCGA 480 $* * * * * * * * * * * * * * * * * * * * * * * * * * * * * * * * * * * * * * * * * * * * * * * * * * * * * * * * * * * *$

GATTTCCTAGAGATGCAGCAGTCTCT 502

GATT TCCTAGAGATGCAGCAGTCTCT 506

$* * * * * * * * * * * * * * * * * * * * * * * * * *$

(B)

Sample B

Astropecten scoparius

Sample B

Astropecten scoparius

AGGTAGCATAATCATTTGCCTTTTAAATGGAGGCTAGTATGAATGGCAAGACGGGGGTTT TTTGCCTTTTAA - TGGAGGCTAGTATGAATGGCAAGACGGGGGTTT $* * * * * * * * * * * * \quad * * * * * * * * * * * * * * * * * * * * * * * * * * * * * * * * *$

Sample B

Astropecten scoparius

AgCTGTCTCTCTTTTAGgAGCTTGAATTTATTATCTTAGTGAAGAAACTAAgATAAgGTC AGCTGTCTCTCTTTTAGGAGCTTGAATTATTATCTTAGTGAAGAAACTAGATAAGG C 108

Sample B

Astropecten scoparius

GT AGGACGAGAAGACCCTATCGAGCTTTAGCTATTAGTTAAAGTTAAGGGTTTTTTATTG 240 GTAGGACGAGAAGACCCTATCGAGCTTTAGCTATTAGTTAAAGTAAGGGTTTTTATG 168

Sample B

Astropecten scoparius

TTAAGCTAATAAAGTTAAAAATTGATTTTACTTAATAATAAGAATAAACTGTTAATAAAg 300 TTAAGCTAATAAAGT TAAAAATTGATTTACTTAATAATAAGAATAACTGTTAATAAG 228 $* * * * * * * * * * * * * * * * * * * * * * * * * * * * * * * * * * * * * * * * * * * * * * * * * * * * * * * * * * * *$

Sample B

Astropecten scoparius

TGT T T TGGT T GGGGCAACCACGGAGAAAAAT CAACCT C CGGTTATAAAATAGAAAAAAT T 360 TGTTTTGGT TGGGCAACCACGGAGAAAATCAACCTCCGGTTATAAATAGAAAAAT 288

SampleC

Astropecten scoparius

ACTATTTTGTGAAATTGAATATTAAGAGTGATCCACTGTGAAAGTATCAAAgGAC 420 ACTATTTTGGAAATTGAAT TATAAGAAGTATCCACTGTGAAATGATCAAAGGAC 348

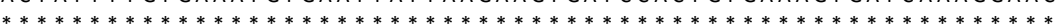

Sample B

Astropecten scoparius

AAGTTACCGTAGgGATAACAGCGTAATTTTTTTGGAGAGTTCATATTGATAAAAA- GTTT AAGTTACCGTAGGGATAACAGCGTAATTTTTTGGAGAGTTCATATTGATAAAAAAGTT 408 $* * * * * * * * * * * * * * * * * * * * * * * * * * * * * * * * * * * * * * * * * * * * * * * * * * * * * * * \quad * * * *$

Sample B

Astropecten scoparius

GCGACCTCGATGTTGGATCGGGACTTCCAGGAGATGCAGCAGT - . CCAAGG . . . . . 528 GCGACCTCGATGTTGGATCGGGACTTCCAGGAGATGCAGCAGTTTCCAAGGGTTGGTCTG 468 $* * * * * * * * * * * * * * * * * * * * * * * * * * * * * * * * * * * * * * * * * * * \quad * * * * * * *$ 
(C)

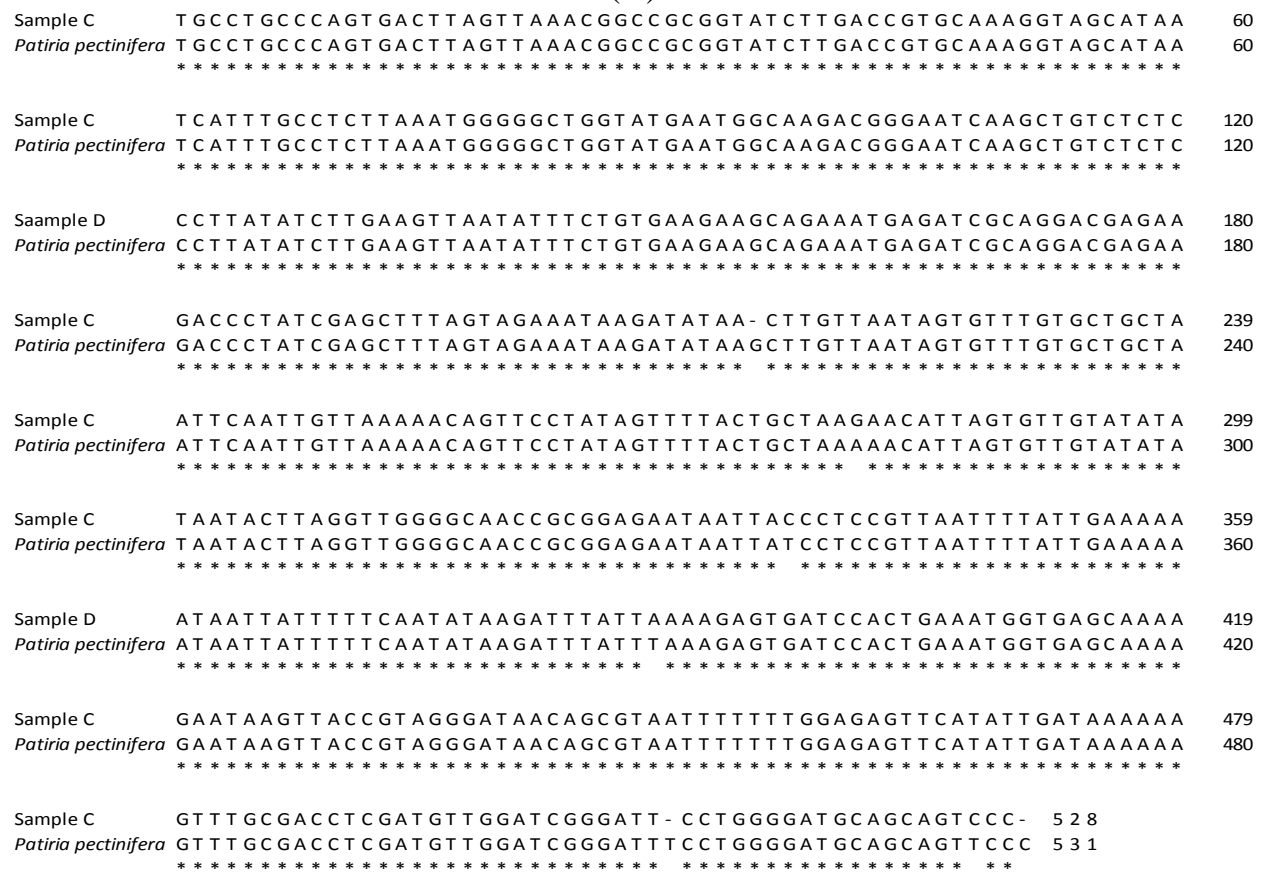

Figure 2. Aligned nucleotide sequences of partial mitochondrial 16S ribosomal RNA gene from $L$. quinaria (A), A. scoparius (B), and P. pectinifera (C) starfish species. The identical nucleotides were shown by dots.

\begin{tabular}{|l|}
\hline Starfish \\
$\Omega$ \\
Extraction with methanol \\
$\Omega$ \\
Treatment with benzene \\
$\Omega$ \\
Ultra filtration (MWCO:1000) \\
$\Omega$ \\
Extraction with $n$-butanol \\
$\Omega$ \\
Extraction with diethyl ether \\
$\Omega$ \\
Lyophilization \\
$\Omega$ \\
Crude extract
\end{tabular}

Figure 3. Schematic flow chart of crude extracts extraction.

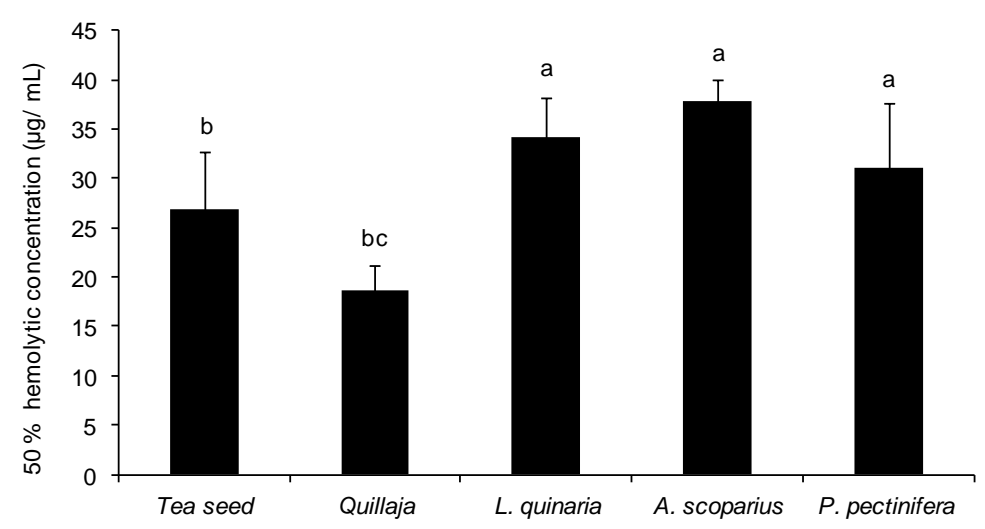

Figure 4. Hemolytic activity of crude extract from starfish against rabbit erythrocytes. Hemolytic activity was expressed as the concentrations of various crude extract that induced hemolysis in $50 \%$ of rabbit erythrocytes, and compared using one-way ANOVA followed by Tukey's test. Significant differences $(p<$ $0.05)$ are represented by different letters over the columns. 


\section{Conclusions}

In this study, we analyzed 16S rRNA gene fragment of mitochondrial DNA and confirmed that 16S rRNA markers are useful and applicable to identify L. quinaria, A. scoparius, and $P$. pectinifera species. The micronutrient results suggested that starfish, one of the marine resources expected to be used as formulation of animal diet and plant growth regulating activity. The hemolytic activity extended by starfish crude extract is very much appreciable for the future development of novel use in pharmaceutical ingredients. Further investigation is required to fully elucidate the hemolytic activity of the secondary metabolites in L. quinaria, A. scoparius, and P. pectinifera.

\section{Conflict of interest}

None to declear.

\section{References}

Amini E, M Nabiuni, J Baharara, K Parivar and J Asili, 2014. Hemolytic and cytotoxic effects of saponin like compounds isolated from Persian Gulf brittle star (Ophiocoma erinaceus). J. Coast. Life Med., 2: 762-768.

Charles G, L Jean, GL Karl, M Vakhtang and P André, 2009. Haemolytic activity, cytotoxicity and membrane cell permeabilization of semi-synthetic and natural lupane- and oleanane-type saponins. Bioorg. Med. Chem., 17: 2002-2008.

Choi S, SY Jung, CH Kim, HS Kim, H Rhim and SC Kim, 2001. Effect of ginsenosides on voltage-dependent $\mathrm{Ca} 2+$ channel subtypes in bovine chromaffin cells. J. Ethnopharmacol., 74: 75-81.

D’Auria MV, L Minale and R Riccio, 1993. Polyoxygenated steroids of marine origin. Chem. Rev., 93: 18391895.

Global Invasive Species Database, 2016. Species profile: Asterias amurensis; http://www.iucngisd.org /gisd/species.php?sc=82 "Accessed 17 May 2016."

Gonzalez-Vega JC, CL Walk, Y Liu and HH Stein, 2013. Endogenous intestinal losses of calcium and true total tract digestibility of calcium in canola meal fed to growing pigs. J. Anim. Sci., 91: 4807-4816.

Imamichi Y and Y Yokoyama, 2013. Purification and characterization of a lectin from the starfish Asterias amurensis. Fish. Sci., 79: 1007-1013.

Inagaki M, Y Ikeda, S Kawatake, K Nakamura, M Tanaka, E Misawa, M Yamada and R Higuchi, 2006. Isolation and structure of four new ceramides from the starfish Luidia maculata. Chem. Pharm. Bull., 54: $1647-1649$.

Ishii T, T Okino and Y Mino, 2006. A ceramide and cerebroside from the starfish Asterias amurensis Luetken and their plant-growth promotion activities. J. Nat. Prod., 69: 1080-1082.

Kim YS, 1969. Selective feeding on the several bivalve mollusks by starfish, Asterias amurensis. Bull. Fac. Fish. Hokkaido Univ., 19: 244-249.

Lee CC, HJ Hsieh, CH Hsieh and DF Hwang, 2014. Antioxidative and anticancer activities of various ethanolic extract fractions from crown-of-thorns starfish (Acanthaster planci). Environ. Toxicol. Pharmacol., 38: 761773.

Luo P, CQ Hu, JJ Xia, CH Ren and X Jiang, 2011. Chemical constituent analysis of the crown-of-thorns starfish Acanthaster planci and potential utilization value of the starfish as feed ingredient for animals. Afr. J. Biotechnol., 10: 13610-13616.

Nina GP, LC Elena, AK Alla and VI Natalya, 2003. Biological activities of steroid glycosides from starfish. Comp. Biochem. Physiol. B., 134: 695-701.

Petersen JK, B Hasler, K Timmermann, P Nielsen, DB Torring, MM Larsen and M Holmer, 2014. Mussels as a tool for mitigation of nutrients in the marine environment. Marine Poll. Bull., 82: 137-143.

Suh SJ, HK Ko, KH Song, JR Kim, KM Kwon, YC Chang, YC Lee, DS Kim, SJ Park, JH Yang, JK Son, MK $\mathrm{Na}$, HW Chang and CH Kim, 2011. Ethylacetate fraction from Korean seaside starfish, Asterias amurensis, has an inhibitory effect on MMP-9 activity and expression and on migration behavior of TNF-induced human aortic smooth muscle cells. Toxicol. In. Vitro., 25: 767-773.

Tamura K, G Stecher, D Peterson, A Filipski and S Kumar, 2013. MEGA6: molecular evolutionary genetics analysis version 6.0. Mol. Biol. Evol., 30: 2725-2729.

Thao NP, BT Luyen, EJ Kim, HK Kang, S Kim, NX Cuong, NH Nam, PV Kiem, CV Minh and YH Kim, 2014. Asterosaponins from the starfish Astropecten monacanthus suppress growth and induce apoptosis in HL-60, PC-3, and SNU-C5 human cancer cell lines. Biol. Pharm. Bull., 37: 315-321.

Wada H, M Komatsu and N Satoh, 1996. Mitochondrial rDNA phylogeny of the Asteroidea suggests the primitiveness of the Paxillosida. Mol. Phylogenet. Evol., 6: 97-106.

Yasumoto T, M Tanaka and Y Hashimoto, 1966.Distribution of saponins in echinoderms. Bull. Jpn. Soc. Sci. Fish., 32: 673-676. 